\title{
The Effect of Food and Air Pollutions on The Public Health in Lebanon
}

\section{Hallal Mahmoud MD* and Saad El Daou}

Lebanese Society of Gastroenterology, American Society of Gastrointestinal Endoscopy, European Society of Gastrointestinal Endoscopy, Lebanon

*Corresponding Author: Hallal Mahmoud MD, Lebanese Society of Gastroenterology, American Society of Gastrointestinal Endoscopy, European Society of Gastrointestinal Endoscopy, Lebanon.

Received: June 20, 2019; Published: July 23, 2019

DOI: $10.31080 /$ ASGIS.2019.02.0062

Food pollution generally defined as the presence of toxic chemicals or poisonous substance (elements or compounds) that always create harmful effects.

The pollutant is not naturally present in food; it can be either foreign substances or a component of the original substance that has exceeded the natural harmless level [1].

While the contaminant is a foreign substance or impurity that introduced from the outside and contaminate the food, it do not always create harmful effects [2].

There are many kinds of food pollutions in the world, some due to human habits and other due to the nature of materials. Pollutants can be categorized into air, water and food that can be bacterial viral fungal or parasitic in nature, the other pollutants are soil, radiation, chemical, oil-spill and noise pollutants [3]. Knowing that all the smog over our cities and the various types of smoke in our home (cigarate, cigar, pipe and narjilah or what we called habble bable smoking Jall these lead to air pollution that poses a major threat to our health and to the climate, these air pollution cause about 7.0 million direct and indirect premature deaths every year, as a result of stoke, heart disease chronic lung disease and cancer [4].

Recently Lebanon, is facing a life threatening conditions due to increase pollution risks and these notified in the WHO recent reports, which says that in Lebanon there are no safe drinkable water [5].

Water Pollution refers to the contamination of water bodies such as water, sea, lakes, ocean, etc. It happens when pollutants are discharged into water without proper treatment. The organic sources of water pollution are food-processing wastes, tree debris, etc. The inorganic sources are acidic industrial discharge, silt, etc. on the other hand the factory pollution accounts for more than half the volume of all water pollution, and produces the most deadly of pollutants, such as phosphates, asbestos, mercury, nitrates, grit, caustic soda, sulfuric acid, sulfur, oils and petrochemicals.

In addition to chemical or electrical pollution that increased recently after the wars and civilizations in our areas [6], Pollution in general is a major issue in Lebanon and other middle east countries and now a day it really concerns every citizen of the country.

The people are seriously affected by many forms of pollution either air or water pollution, in Lebanon air and water pollution represent the greatest risk or thread towards the Lebanese health, according to Lebanese study done at AUB (American university of Beirut ) [7] showed 93\% of Lebanese population living in Beirut are exposed to high levels of air pollution, which attributed wear and tear of tires in every political occasions and due to incomplete consumption of fuel, which is two time more than the recommended by WHO. According to 2010 national report the average nitrogen dioxide concentration was 58 microgram per cubic meter of air and this exceeds the maximum average concentration recommended by WHO [8] and now in 2019 we are sure that it has further deterioration.

This heavy pollution increase the public health care costs and affect the quality of life and the increase the workdays losses [9]. Water polluted by chemicals such as heavy metals, lead, pesticides and hydrocarbon can cause hormonal and reproductive problems, damage to the nervous system, liver and kidney damage and can- 
cer - to name a few, Being exposed to mercury causes Parkinson's disease, Alzheimer's, heart disease and death.

We noticed in the last decade increasing in both incidence and prevalence of infectious and contagious diseases and these are proved in the labs results and documented in the Lebanese hospitals and in the ministry of health $(\mathrm{MOH})$ register [10].

The two studies in contamination-exposed children's draw a disquieting conclusion: $23 \%$ of global deaths are attributable to modifiable or preventable environmental risk factors, and 1.7 million of the 5.9 million deaths per year in those under 5 yrs of age [11].

Rapid urbanization has also left its signature on the environment. Coastal waters show the effects of untreated sewage disposal, particularly near Beirut, and of tanker oil discharges and oil spills. The water pollution problem in Lebanon is in part due to the lack of an internal system to consistently regulate water purification. The nation has about $5 \mathrm{cu} \mathrm{km}$ of renewable water resources [12].

All over the world, there is migration form villages toward cities where the pollution is high due to civilization, the WHO lists the most dangerous pollutants and these are polycyclic aromatic hydrocarbons (PAHs), mercury, sulfur and nitrogen dioxide in addition to carbon monoxide

However rural areas are not lacking in contaminants because the invasion of agrochemical materials and charcoal productions in addition to increase the waste materials amount which contain plastic, nylon and other toxic agents. According to the WHO reports our houses contains a lot of hazardous ingredients in clothes, toys, furniture, carpets and computers like chromium VI, lead, arsenic, mercury cadmium, polybrominated diphenyl ethers (PBDEs), formaldehyde and fungicides as well Mercury can be found in cosmetics, fluorescent light bulbs, batteries etc. all these pollutants if improperly handled or disposed of, can pollute our air, soil, food and water.

With over a billion smokers in the world today, smoking is also an increased pollutant in modern life, and its tragic effects have been already well documented: exposure increases the risk for sudden infant death syndrome(SIDS) in infants and for altered development in children, and compounds the effects of ambient air pollution on the respiratory systems of children of all ages [12].
Food contamination can trigger anything starting from mild discomfort to life threatening condition such as metabolic, hormonal or nervous system problems and it also can lead to various types of cancer on the long run if accumulated in our bodies, in the literature there are more than 70 million cases of food borne illnesses in USA yearly resulting in approximately 5000 deaths per year.

Food can be polluted if exposed to any potential pollute including growing of food (e.g. crops, fruits, vegetables) in polluted soils, solid wastes (e.g. mine tailings) or areas with polluted air, ground water irrigation of grown food (e.g. vegetables, fruits, crops) with water; agricultural treatments with pesticides, herbicides; agricultural application of sewage sludge and/or polluted fertilizers (which contain ash from power plants); consumption of polluted water and/or food by fish or other animals; food processing, packaging, and handling; propagation and concentration of pollutants through the food chain.

The Food pollution risks depend on a variety of factors, including: Type of pollutant - while any pollutant present in food may pose a health risk, the pollutants that are persistent and bio accumulative are those that pose the higher risks because they may accumulate in food over time resulting in concentrations much higher than in a surrounding environment (e.g., accumulation of persistent chemicals such as organ mercurial compounds or PCBs in fish).

Presence of hormones in our food can led to serious risks,for example, presence of artifial hormone (rBGH) in cow milk that used to increase milk production may play an important role in some types of cancer in humans, on the other hand the fish which considered a safe alternative is more dangerous than other food due to potential exposure to organic contaminants in the sea, river and or lake water, the contaminated fish can transmit the pollute to any bird, animal or human when he eating the affected fish [13].

However, healthy individuals may also develop food-poisoning disease and any one may be at risk [14].

The main and the most common reason that led to increase the incidence is multi factorial and related to the poor sanitation and to the crowdenence in the institutes and refuges places and due to unhealthy waste management in addition to water pollution in the rivers and lakes and there are many national and international reports indicate and document the severity of pollution in Lebanese drinking water, There are increased incidences in the malig- 
nancies and chronic illness which are related to theses pollution and if compare the incidence of these diseases in comparison to the old era will found its proportionally increased with civilization and with the increase risk of chemical and organic waste material.

We should work hardly and effectively to treat and prevent these pollution revolution by control the water sources, control the waste management, prevent importing any food that may be polluted and we should improve the MOH laws to become suitable with the recent international laws and we should work in multidisciplinary teams between all the involved ministries and the human resources and the civil organization to reach these goals An alternative that may ensure production of less polluted food was recently proposed in Japan.by growing vegetables in special factories with unpredictable effect of weather and environmental pollution, this process is proposed by the Ozu corporation in Tokyo [15].

An important question should be answered, is there a different between ugly food and blemish-free food? ugly food means the food which have some shape defect and are not identical to each other, because ugly food were not treated or adapted by chemicals and hormones in fact the answer is yes, the ugly food is better, less polluted, more natural and significantly cheaper [16], consuming ugly food can solve part of global climate pollution [17]. The fact that the vegetables, crops and trees get contaminated from the environment comes from their ability to extract environmental pollutants through their roots along with water and nutrients in other hand some plants (non-edible species) are used to remediate or moderate polluted soil by extracting pollutants from soils, (an innovative remediation called phytoremediation) [18].

\section{Recommendations for Prevention of Pollution}

The best way to solve problem is to understand it, learn about it and be aware about the harmful and toxic effects of littering.

Discuss the problems with friends and family; keep talking about it, in the audiovisual and social media.

Start educational programs about sanitation and pollution in the schools in order to achieve a healthy educated community from the childhood.

The WHO has conducted extensive research on environmental education to prevent pollution in the communities and to reduce the medical care costs and social costs; the finding showed that educations campaigns and prevention measures are helpful in their communities [19].

There are things we can start doing it now to improve the health of our families and the environment. Among the measures we can take are the following:

- Follow recycling instructions as per your country.

- $\quad$ Promote physical activity by providing safe parks and facilities for safe walking and cycling.

- Carefully read labels for household items and avoid known toxic contaminants.

- Keep contaminants safely stored away in well-aired spaces.

- $\quad$ Avoid tobacco, alcohol, drugs and other toxicants during and before pregnancy.

- $\quad$ Ensure access to safe drinking water, sanitation, and hygiene by constant testing and maintenance.

- $\quad$ Promote good nutrition by providing fresh fruit and vegetables.

\section{Bibliography}

1. https://en.wikipedia.org/wiki/Pollutant

2. https://www.merriam-webster.com/dictionary/contamination

3. https://www.livescience.com/22728-pollution-facts.

4. www.theworldcounts.com/stories/How-Does-Pollution-Affect-Humans

5. https://www.importantindia.com/6910/short-paragraphon-pollution

6. https://tunza.ecogeneration.org/ambassadorReportView. jsp?viewID=13287

7. https://fanack.com/pollution/pollution-in-lebanon

8. https://www.who.int/airpollution

9. Nature Middle East Daily star.

10. www.moph.gov.lb

11. Sahar Azar and Safa Azar. "Waste Related Pollutions and Their Potential Effect on Cancer Incidences in Lebanon". Journal of Environmental Protection 7 (2016): 778-783. 
12. Lebanon|Encyclopedia.com

13. https://www.environmentalpollutioncenters.org/water/

14. https://www.environmentalpollutioncenters.org/food/diseases/

15. http://time.com/3761942/why-people-are-falling-in-lovewith-ugly-food/

16. http://www.feedingamerica.org/about-us/how-we-work/ securing-meals/reducing-food-waste.html

17. https://www.theguardian.com/environment/2016/jul/13/ us-food-waste-ugly-fruit-vegetables-perfect

18. http://www.fao.org/save-food/resources/keyfindings/en/

19. https://keeplebanongreen.wordpress.com

Volume 2 Issue 6 August 2019

(C) All rights are reserved by Hallal Mahmoud MD and

Saad El Daou.

Citation: Hallal Mahmoud MD and Saad El Daou. "The Effect of Food and Air Pollutions on The Public Health in Lebanon". Acta Scientific Gastrointestinal Disorders 2.6 (2019): 39-42. 